\title{
IMAGEM DO PROFESSOR \\ E ATRATIVIDADE DA DOCÊNCIA: ENUNCIADOS SOBRE CARREIRA DOCENTE NA MÍDIA IMPRESSA
}

\author{
Ana Paula Rufino dos Santos*
}

\begin{abstract}
RESUMO
O presente texto investe na análise da produção de discursos sobre a atratividade da carreira docente em textos jornalísticos que abordam diversos assuntos relacionados à educação básica, com vistas a compreender, a partir da intersecção entre "imagem do professor na mídia" e "atratividade da docência", práticas discursivas de produção de representações da docência enunciadas em textos de reportagem sobre a atratividade da carreira docente divulgados pela mídia impressa. Para o exame de 04 reportagens veiculadas entre 2010 e 2013 sobre a carreira docente no Brasil do arquivo on-line da Fundação Victor Civita sobre a importância dos professores e a qualidade da educação, opera com a analítica foucaultiana do discurso com vistas a ler, descrever e discutir "como o discurso atua e como se revela" (FOUCAULT, 2006). A análise dos enunciados da mídia impressa permite afirmar que as formações discursivas produzidas selecionam e orientam processos de representação da docência e de valorização do professor como práticas de significação.
\end{abstract}

Palavras-chave: Atratividade da docência. Discurso. Imagem do professor.

\begin{abstract}
THE IMAGE OF THE TEACHER AND THE ATTRACTIVENESS OF TEACHING: STATEMENTS ABOUT THE TEACHING CAREER IN PRINT MEDIA

This text invests in analyzing the production of discourses on the attractiveness of the teaching career in journalistic texts addressing various issues related to basic education, in order to understand, from the intersection between "the image of the teacher in media" and "the attractiveness of teaching", discursive production practices of representations of teaching set out in reports on attractiveness of teaching published by print media. For the analysis of 04 reports published between 2010 and 2013 on the teaching career in Brazil from Victor Civita Foundation online archive about the importance of teachers and quality of education, we operate Foucault's analytical discourse in order to read, describe and discuss "how discourse operates and how it reveals" (FOUCAULT, 2006). The analysis of statements of print media suggests that the discursive formations select and direct the representation processes of teaching and appreciation of teachers as signifying practices.
\end{abstract}

Keywords: Attractiveness of teaching. Discourse. Teacher's image.

\footnotetext{
* Mestra em Educação pela Universidade Federal de Pernambuco (UFPE). Professora de disciplinas pedagógicas na graduação e pós-graduação da Faculdade Europeia de Administração e Marketing (FEPAM/ISEAD) e Universidade do Vale do Acaraú (UVA/ISEAD), em Recife. Professora substituta no Departamento de Métodos e Técnicas de Ensino da Universidade Federal de Pernambuco (UFPE). Doutoranda em Educação na Universidade Federal de Pernambuco (UFPE). aprsantosufpe@yahoo.com.br
} 


\section{Introduzindo a questão}

O debate sobre a atratividade da docência situa-se no âmbito das discussões sobre valorização da docência. E esta, segundo Neto (2006), junto com outras questões, forma um campo temático do qual a profissionalização, a formação e a carreira são parte integrantes. Vale dizer que no campo da formação de professores esse debate envolve estudos sobre as políticas de formação e profissionalização e seu processo de profissionalidade. Tal questão tem ocupado, nas últimas décadas, grande espaço nas pesquisas educacionais, em especial nos estudos sobre formação de professores.

Nos últimos anos, não só no Brasil como em outros países, estudos na área da formação de professores apontam a crescente preocupação de pesquisadores, de governos e de gestores de políticas públicas para a educação com o atual ou iminente déficit de professores em todos os níveis de ensino. Como apontam Paiva e Souto (2013), esse fato decorre, fortemente, tanto do abandono do magistério quanto da baixa procura dos jovens pela profissão de professor. Isso se explica, principalmente, pela pouca atratividade da profissão docente em relação a várias outras profissões que exigem o mesmo nível de formação acadêmica.

Tais pesquisas assinalam um quadro de desvalorização da carreira docente, como propõem Gatti, Barreto e André (2011), se fazendo necessário considerar o problema e discutir que fatores interferem nesse posicionamento, ou seja, por que tem decrescido a demanda pelas carreiras docentes, especialmente na educação básica.

Contudo, também revelam que, no Brasil, “a importância dos professores no conjunto geral dos empregados formais, não é menor do que nos países desenvolvidos" (GATTI; BARRETO; ANDRÉ, 2011 , p. 20), além de representar $80 \%$ do funcionalismo público. Ainda que a sociedade brasileira tenha como discurso a importância da educação, não há ainda a percepção dessa temática como uma questão de urgência, prioritária, que deve ser, portanto, objeto de políticas incisivas por parte do poder público, e de ações diretivas capitaneadas por organizações civis e sindicatos.

Nesta acepção, Gatti, Barreto e André (2011) apontam várias facetas que se entrecruzam na constituição da profissionalização docente e são examinadas no estudo citado: legislação, características da formação inicial presencial e a distância, modelos especiais de formação implementados por administrações públicas, perfil dos professores e dos licenciandos, aspectos relativos à educação continuada nas redes de ensino, dados gerais sobre salário e carreira. Gatti e Barretto (2009, p. 255) destacam que "salta à vista a necessidade de adoção de uma estratégia de ação articulada entre as diferentes instâncias que formam professores e as que os admitem como docentes", bem como a necessidade de "conseguir-se consensos quanto aos rumos da educação nacional, das estruturas formativas de docentes para a educação básica e dos currículos respectivos", questões estas que remetem diretamente à questão das políticas educacionais e, dentro destas, às políticas voltadas aos docentes.

A atenção a essa temática e a preocupação dos vários segmentos da sociedade quanto ao desempenho da educação básica, de acordo com Gatti, Barreto e André (2011), têm aparecido na mídia com frequência, ao lado de movimentos de organizações civis e de entidades científicas e profissionais, na perspectiva de discutir a qualidade da educação brasileira, tida como insatisfatória em vários aspectos, ainda que muitas vezes em direções opostas.

Diante das questões apresentadas, a presente discussão intenta abordar a atratividade docente na forma como a mídia impressa retrata este evento discursivo.

Para desenvolver discussão, toma como base o debate sobre atratividade da docência, como Gatti e Barreto (2009), Gatti e colaboradores (2010) e Gatti, Barreto e André (2011), os quais investem na análise de questões no âmbito da formação de professores, a atratividade da carreira docente, associado a estudos no campo dos Estudos Culturais (EC), como Costa (2003), Giroux (1995) e Silva (1995), que têm como ênfase a análise do conjunto da produção cultural de uma sociedade em seus diferentes textos e suas práticas.

O presente texto associa-se a estudos no campo da formação de professores que apontam um conjunto de proposições que dizem respeito à dimensão cultural relacionada à docência e à representação docente presente no imaginário brasileiro, desta- 
cando o papel da mídia na construção do imaginário social de valorização do professor e do ensino público. Na medida em que investe na análise da produção de discursos sobre a atratividade da carreira docente na mídia, em revistas que abordam diversos assuntos relacionados à educação e à educação escolar, com vistas a compreender as práticas de produção de subjetividade docente enunciadas em textos de reportagens sobre a atratividade da carreira de professor/professora da educação básica divulgados pela mídia especializada. De maneira mais específica, analisa as intersecções entre "imagem do professor na mídia" e "atratividade da docência" nos enunciados da mídia impressa nos textos de reportagem.

\section{Valorização da carreira docente no Brasil: algumas questões}

Em pesquisa encomendada pela UNESCO sobre carreira docente, Gatti e Barreto (2009) consideram que a valorização da profissão de professor da educação básica passa pela própria formação dos docentes e pelas condições de carreira e de salários vinculadas a ela, bem como pelas condições concretas de trabalho nas escolas e políticas que visem contribuir para o desenvolvimento da profissionalidade (competência, qualificação mais aprofundada). Além disso, indicam que a profissionalização dos professores demanda a superação de alguns entraves para o exercício da docência na direção de melhoria da formação e das aprendizagens das novas gerações e apresentam uma série de aspectos fundamentais para uma análise sobre a valorização/desvalorização da docência no âmbito das discussões sobre a educação básica. Dentre esses aspectos apontam que para a valorização da carreira de professor, o primeiro a ser destacado diz respeito aos cuidados com sua formação na graduação. O prestígio pode começar por aí, donde a colocação enfática da necessidade de se reformular e manter constantemente atualizada a formação inicial básica dos professores, contando com formadores de professores preparados para conseguir que seus alunos (futuros professores) aprendam a ensinar. Ou seja, começar a qualificar melhor os futuros professores na graduação.
E acrescentam que outra questão a ser considerada diz respeito à existência de concurso para ingresso na carreira, sendo este considerado fator primeiro de detecção da qualificação dos candidatos à docência. $\mathrm{O}$ concurso para a carreira de magistério no setor público é obrigatório pela legislação brasileira. No entanto, muitas vezes esses concursos ou não são realizados, contratando-se professores em condição transitória, ou deixam muito a desejar em sua concepção e execução, o que os torna insuficientes para verificação de qualificação profissional mínima.

Outro ponto a ser considerado nessa análise é a avaliação de desempenho em estágio probatório, que não tem sido regulamentada, portanto, não é praticamente implementada. Para Gatti e Barreto (2009) e Gatti e colaboradores (2010), com quem concordamos, o estágio probatório, quando bem conduzido, cria uma aura de responsabilidade e uma imagem pública de seriedade, na ideia de garantia para os pais de competência profissional. Agregaria valor à carreira. Além da regulamentação e da implementação do estágio probatório como elemento de valorização profissional, outra questão a ser considerada são as políticas de formação de professores na direção de qualificar melhor a educação básica, que passam pela formação pré-serviço e continuada dos docentes, mas passam também pela renovação constante da motivação para o trabalho do ensino, pela satisfação com a remuneração e a carreira, o que implica a implementação de várias ações de gestão do pessoal do ensino de modo integrado. E lembram que políticas isoladas, ações pontuais não interligadas por uma finalidade comum, na direção de construção de um valor social profissional, não conseguem impacto suficiente para a melhoria das aprendizagens nos sistemas escolares.

Nesta perspectiva, Gatti e Barreto (2009), ao pontuarem sobre a profissionalização e profissionalidade docente, destacam que ações de diversas naturezas em relação à profissionalização docente necessitariam evidenciar melhorias nas perspectivas de carreira e alterar o imaginário coletivo relativo a essa profissão, tanto na sociedade em geral, como entre os próprios professores, o que passa por devolver a esses profissionais a confiança em si mesmos, o que pode ser conseguido com políticas adequadas que perdurem no tempo. Em sua 
opinião, se faz necessário considerar que docentes não são autômatos sociais cujas ações obedecem unicamente a estímulos externos, tais como as leis, decretos, circulares e regulamentos. São pessoas com ideias, imaginação, representações, e gozam de certa autonomia, mesmo que seja parcial. Daí a importância de conhecer a subjetividade dos agentes sociais para compreender o que fazem e por que o fazem.

Nesse sentido, as políticas públicas não podem ignorar esse fato. $\mathrm{O}$ sentimento de menos-valia ${ }^{1}$ da categoria, expresso em tantos e tantos estudos, passa pela condição salarial e as perspectivas de carreira, como sinalizam as pesquisas. Gatti e Barreto (2009) alertam que os planos de carreira encontrados nas redes não mostram a possibilidade real de professores "subirem na carreira" sem deixar a sala de aula. Tal situação desmotiva bons candidatos a professor, e também os bons professores, que se sentem desvalorizados e acabam por procurar outra função fora da sala de aula para obter promoção significativa. Além de também criar a representação de que ficar na sala de aula não propicia uma carreira recompensadora social e financeiramente.

Para além dessas questões, Scheibe (2010) lembra que há uma grande pressão para que os professores apresentem melhor desempenho, principalmente para que os estudantes obtenham melhores resultados nos exames nacionais e internacionais. As críticas ressaltam, sobretudo, os professores como mal formados e pouco imbuídos de sua responsabilidade pelo desempenho dos estudantes. A partir daí, os diversos níveis governamentais vêm criando mecanismos que visam ampliar o controle do exercício profissional, mediante exames de certificação de competência, associados à implantação de incentivos financeiros. Ao passo que os salários de professores da educação básica continuam baixos, com carreiras

1 É importante lembrar que, segundo Karl Marx, o valor do trabalho não é uma grandeza concreta: o operário não vende sua força ou sua habilidade. Pelo contrário, o progresso da mecanização garante um padrão uniforme de produtividade dentro de cada ramo de atividade e para cada tipo de ocupação, igualando-os. O termo "menos-valia" está sendo empregado no texto buscando caracterizar a sobrevalorização dos aspectos econômicos que contribui para a desvalorização salarial de profissões, como é o caso da docência em relação a outras profissões e suas implicações de efeitos na criação de uma representação dos profissionais da área. que não oferecem clareza de percurso, imaginário coletivo de desmotivação.

Diante do exposto concordamos com a afirmação de Gatti e Barreto (2009), de que complexa é a trama que nos oferecem os dados trazidos nos diversos estudos, considerando, de um lado, os aspectos relativos ao trabalho dos professores, as características dos docentes, da formação em serviço e continuada - como elementos que compõem o cenário das atividades de ensino-aprendizagem nas escolas do país -, e, de outro, as posturas normativas, as condições de formação e socioculturais dos licenciandos em diversas áreas, sinalizando perspectivas de futuro para a qualidade da educação.

\section{A atratividade docente e a mídia impressa: o corpus de análise}

Para este estudo foi realizada uma pesquisa exploratória, no site da Fundação Victor Civita ${ }^{2}$ (FVC), de textos de relatórios e artigos de pesquisas educacionais sobre atratividade da docência a partir da intersecção dos conceitos de atratividade, carreira e docência. Dentre os diversos textos midiáticos escolhemos analisar a reportagem.

Por se tratar de um texto de divulgação que utiliza determinados procedimentos discursivos que têm características específicas em razão de sua função social, "Em sua engrenagem discursiva utiliza informações procedentes do discurso técnico-científico, o modo de elaboração deste novo discurso é específico, pois está determinado por concepções próprias de produção e de difusão pelo uso das palavras, mesmo em um mundo governado pela imagem" (CATALDI, 2007, p. 158).

De um conjunto de 17 textos jornalísticos escolhidos, foram selecionadas quatro (04) reportagens publicadas entre 2010 e 2013, sobre carreira docente no Brasil. Tais textos fazem parte do arquivo on-line da área de Estudos e Pesquisas da Fundação Victor Civita (FVC), a qual reúne relatórios de pesquisas e reportagens de diversos veículos de

2 A Área de Estudos e Pesquisas da FVC, criada em 2007, tem como principal objetivo a produção e disseminação de informações resultantes de pesquisas educacionais entre formuladores de políticas públicas, pesquisadores, institutos e universidades dedicados à pesquisa educacional e à formação de educadores e gestores, bem como entre Organizações Não Governamentais (ONGs) com foco na Educação. 
comunicação/informação sobre a importância dos professores na qualidade da educação, em parceria com a Fundação Carlos Chagas (FCC).

\section{Imagem do professor e atratividade: discursos sobre docência na mídia impressa}

A metodologia adotada opera com a analítica foucaultiana do discurso utilizando-se das categorias de interdição e exclusão - consiste, portanto, em ler, descrever e discutir como o currículo da mídia atua, "como funciona, como o discurso se revela" (FOUCAULT, 2006, p. 37). Isso significa colocar foco nas estratégias e técnicas discursivas para descrever e analisar o que o discurso "faz aparecer" no terreno da educação, "como objetiva", o que produz e o que subjetiva. Para tanto, atenta-se ao vocabulário utilizado, às estratégias e táticas adotadas, bem como às técnicas corporificadas no discurso investigado.

Nessa acepção, as imagens, fotografias, cores, personagens, mapas, quadros, gráficos, tabelas, desenhos são considerados táticas que contribuem para dar efeito de verdade ao discurso divulgado. Assim, elas não são tomadas de modo separado das "coisas ditas" e escritas nesses materiais.

Nesta seção estaremos, à moda foucaultiana, fazendo uma reescrita dos discursos sobre a atratividade da carreira docente na mídia, em textos midiáticos que abordam a educação e a educação escolar, com vistas a compreender as práticas de produção de subjetividade docente enunciadas em textos de reportagens sobre a atratividade da carreira de professor/professora da educação básica divulgados pela mídia impressa.

A presente investigação foi desenvolvida apoiando-se na epistemologia dos Estudos Culturais (EC), os quais estão profundamente preocupados com a relação entre cultura, conhecimento e poder. Sobre os quais vale pontuar que em seus desdobramentos, os EC investem intensamente nas discussões sobre a cultura, colocando a ênfase no seu significado político; estão profundamente preocupados com a relação entre cultura, conhecimento e poder (GIROUX, 1995). E mostram que a sociedade contemporânea encontra-se imersa no mundo audiovisual, atribuindo à mídia importância e valor enquanto meio de aprendizagem, informação e produtora de narrativas de nosso tempo.

Sob este entendimento, como propõe Silva (1995), as narrativas constituem uma das práticas discursivas mais importantes. Elas contam histórias sobre nós e o mundo e nos ajudam a dar sentido, ordem, às coisas do mundo e a estabilizar e fixar nosso eu. E o poder de narrar está estritamente ligado à produção das identidades sociais. As narrativas não apenas nos ajudam a dar sentido ao mundo, a torná-lo inteligível; elas constituem o mundo e fornecem elementos para nos construir. Na medida em que elas são cruzadas pelas linhas de poder, não existem num campo tranquilo de imposição.

Nessa abordagem, a relação entre linguagem e pedagogia deve ser entendida, para além de sua importância pedagógica estrita, como veículo de interpretação. Ela deve ser também entendida como um local de contestação social. "Como parte de uma luta mais ampla; como um discurso de possibilidade, considerando a linguagem tanto como uma política da representação quanto como uma prática social através da qual as identidades são re-configuradas" (SILVA, 1995, p. 96). Pode-se dizer que na perspectiva dos Estudos Culturais, como afirma Costa (2003) nas práticas de significação, o conhecimento está sob o peso das relações de poder.

A publicidade, os textos jornalísticos, a literatura, a televisão, a música, o cinema são peças importantes de análise para os Estudos Culturais. E estão unidos por uma abordagem cuja ênfase recai na importância de se analisar o conjunto da produção cultural de uma sociedade, seus diferentes textos e suas práticas, para entender os padrões de comportamento e a constelação de ideias compartilhadas por homens e mulheres que nela vivem.

Foucault (1995) propõe que as formas modernas de poder atuam na subjetividade do indivíduo à sujeição desse indivíduo (ser controlado por outro) e explora a articulação entre poder e saber, em cujo interior se produz o sujeito. "Os processos de subjetivação estão diretamente relacionados às experiências que o sujeito faz de si mesmo, num jogo de verdade em que é fundamental a relação consigo" (FOUCAULT, 1995, p. 14). São sempre situados e amplamente diversos, nos modos de existência que produzem, de acordo com a época e o tipo de construção social. 
Assim, entende-se que o conceito de subjetivação sugere pensar que as identidades são formadas e transformadas continuamente em relação às formas pelas quais somos representados ou interpelados nos sistemas culturais que nos rodeiam (HALL, 2000), bem como constituídas em muitas instâncias e espaços.

Assim como a identidade do professor também não é algo dado, mas, antes, como afirma Nóvoa (2009), um lugar de lutas e de conflitos, é um espaço de construção de maneiras de ser e de estar na profissão. Por isso um processo identitário sob a mescla dinâmica que caracteriza a maneira como cada um se sente e se diz professor. Contudo, é preciso lembrar que na sociedade da "cultura da mídia e do consumo" (COSTA, 2009), a mídia, por meio de diferentes estratégias de subjetivação produz enunciados que fazem emergir um discurso pela qualidade da educação tecido na enunciação de uma representação de professor a partir de aspectos subjetivos como aquele que precisa possuir habilidade técnica para atender as demandas tecnológicas e que seja emocional e relacionalmente "o exemplo", aquele que inspira ou, na mesma moeda, desestimula a escolha pela docência para as próximas gerações.

Filha de professor cresceu vendo o exemplo do pai. 'Um entusiasta pela profissão', afirma. [...] 'Minha motivação e gosto por ensinar veio do exemplo dele'. (VALENZA, 2010, p. 4).

[...]. A principal joia da coroa de uma estrutura educacional deve ser a sala de aula. Esses são os metros quadrados mais nobres, e quando o seu entorno não é bom, a sala também é maculada. Aos governantes compete instituir planos de carreira estimulantes e critérios de meritocracia. [...] Não conheço missão maior e mais nobre que a dirigir as inteligências jovens e preparar os homens do futuro. (VALENZA, 2010, p. 1).

Nessa construção discursiva, na forma como elege os elementos do discurso pela educação básica aparece uma interdiscursividade com o discurso da escola republicana, ${ }^{3}$ onde o professor se faz representado por uma identidade simultânea

\footnotetext{
3 Neste sentido, como propõe Brayner (2008) a educação na perspectiva republicana representa o discurso da possibilidade de superação das desigualdades sociais. Uma escola voltada para as classes mais fragilizadas da sociedade e poder lhes oferecer a possibilidade de se tornarem visíveis através da palavra e da ação.
}

de "operário" e "apóstolo", a qual considerava que os professores tinham um papel central na civilização e nacionalização do país: "Aos professores só há uma coisa a dizer, escrevia o inspetor: [...] a vossa vida precisa ser um espelho cristalino onde se resistam e donde irradiem todas as virtudes possíveis e imagináveis. Instruí, mas educai - educai principalmente". (NORTE, 1920 apud MADEIRA, 2010, p. 68).

Nessa análise, aos professores caberia a responsabilidade pelo progresso e a confiança depositada. Um discurso pautado no reconhecimento de que a civilização e o progresso do país seriam produtos do trabalho e da educação. Contudo, Gatti e colaboradoras (2011) lembram que a docência pertence a um campo profissional e que o reconhecimento dos docentes da educação básica como profissionais essenciais ao país passa pela oferta de carreira digna e remuneração condizente com a formação deles exigida e com o trabalho deles esperado. E acrescenta que não se pode camuflar isso com sofismas que não contribuem com a profissionalização dos professores e a construção de sua identidade profissional com características comuns valorizadas.

Para além desses aspectos, há outros elementos igualmente importantes em direção à melhoria da qualidade da educação, como a valorização social da profissão, os salários, as condições de trabalho, a infraestrutura das escolas, as formas de organização do trabalho escolar, a carreira - "que devem fazer parte de uma política geral de apoio aos docentes. Sendo estes alguns dos fatores que não podem ser esquecidos, nem desconsiderados no delineamento de políticas para os professores" (GATTI et al. 2011, p. 15).

Parece evidente nessa construção discursiva o que Foucault (1995) denomina de procedimentos de exclusão do discurso, que oculta ou deixa de evidenciar elementos do discurso para aparecerem na forma de acontecimento. Nesta perspectiva, os aspectos socioeconômicos e políticos apontados por vários estudos sobre a valorização da carreira docente são silenciados.

Vale lembrar, como apontam Gatti e Barreto (2009), mencionadas anteriormente, que a valorização da profissão de professor da educação básica passa pela formação dos docentes e pelas condições de carreira e de salários vinculadas a ela, 
bem como pelas condições concretas de trabalho nas escolas, políticas que visem contribuir para o desenvolvimento da profissionalidade (competência, qualificação mais aprofundada); são aspectos fundamentais para uma análise sobre a valorização/ desvalorização da docência no âmbito das discussões sobre a educação básica.

A análise das formações discursivas produzidas advindas das reportagens evidenciou também a emergência de certas imagens que orientam processos de representação. As representações, por sua vez, envolvem as relações entre os planos da significação, da realidade e as imagens decorrentes, possuem vínculos com a realidade, porém correspondem a um nível de construção e não de reprodução estrita do mundo. Este aspecto é submetido a estratégias de disfarce, no discurso midiático.

Quem se depara com Mário Gattica, óculos escuros, terno preto, alto, musculoso, lutador de arte marciais, cuidando da segurança de uma casa noturna da rua Augusta, jamais poderia imaginá-lo como professor de filosofia de escola pública. 'Gostaria apenas de dar aulas', conta - apesar de, algumas vezes, ele se sentir mais vulnerável fisicamente dentro de uma escola do que evitando ou assaltos na madrugada. (DIMENSTEIN, 2010).

[...] 'Eles passam por problemas de saúde, estresse, depressão, porque a pressão do dia a dia é muito grande', destaca. A consequência é o índice de renovação constante. [...] ' $\mathrm{Na}$ iniciativa pública essa rotatividade não é alta porque a grande maioria é concursado e estável', diz o presidente do Sinteemar, Éder Adão Rossato. (VERZOLA, 2013).

Nessa construção discursiva Citelli (2012) ajuda-nos a perceber que duas grandes categorias narrativas tendem a representar a figura do professor: uma representação comprovadora e outra de predicação. A primeira é composta tanto por registros e discursos negativos (falta de preparo dos professores, violência escolar, greves etc.), quanto pela menção a experiências de sucesso. Na representação predicativa, o discurso indica sucessos e fracassos, mas é observado, nos estudos de caso sobre o espaço do trabalho, o professor, bem como suas entidades e órgãos de classe.

Observa-se nos enunciados em questão uma espécie de representação comprovadora. Um cruzamento de enunciados do campo midiático e os enunciados oriundos da experiência social cotidiana sobre o professor e a profissão docente. Assim, o discurso midiático aparece estruturado com enunciações que tendem a ressaltar a importância da educação, mas oferece à mesma um tratamento aligeirado em relação aos enunciados que apontam a relevância dos professores, porém enxergam a docência como uma profissão indesejada.

O discurso pela qualidade da educação básica emerge da contradição entre a imagem do professor e a representação da profissão docente: "ao mesmo tempo em que a docência é louvável, o professor é desvalorizado, social e profissionalmente" (GATTI et al, 2011, p. 20).

O conceito de representação, da forma como está sendo apreendida neste texto, diz respeito a um processo cultural que, por sua vez, diz respeito às práticas de significação e aos sistemas simbólicos por meio dos quais se produzem significados, posicionando-nos como sujeito, ou seja, ao produzirmos significados damos sentido à experiência, ao que somos. Ou seja, "é por meio dos significados produzidos pelas representações que damos sentido à nossa experiência e àquilo que somos" (SILVA, 2009, p. 17).

Assim, tal como defende Louro (1997), as representações são apresentações, são formas culturais de referir, mostrar e nomear um grupo ou um sujeito. A autora entende, portanto, que as representações dos sujeitos dizem algo sobre esses sujeitos, delineiam seus modos e traços, definem seus contornos, enfim, são formas culturais de referir-se aos sujeitos e de afirmar se um indivíduo pode ou não ser identificado como pertencendo a um determinado grupo. "[...] as representações produzem sentido e certamente se transformam e se distinguem - histórica e socialmente" (LOURO, 1997, p. 99). Ou como aventa Silva (2009, p. 18), quando afirma que esses sentidos que as representações produzem são criações sociais múltiplas, pois diversos grupos e vozes desenham os sujeitos, os quais, por sua vez, se adaptam ou contrapõem a essa caricatura, ou seja, os significados que as representações acabam produzindo não preexistem no mundo, mas eles têm que ser criados, e são criados socialmente, são criados através de relações de poder. 
A análise dos enunciados fez emergir outro enunciado sobre a educação básica na intersecção entre os conceitos de imagem do professor e atratividade da docência, o enunciado do inevitável fim da profissão. Na forma como se estruturam no título de reportagens:

O que você não quer ser quando crescer? (DIMENSTEIN, 2010).

Professor vai virar artigo de luxo. (VALENZA, 2010).

\section{Prestígio zero. (BERTOLOTI, 2010).}

Os enunciados se instituem sob um discurso de naturalização da desvalorização da profissão docente como se profissão não fosse uma construção social, em uma realidade dinâmica e contingente calcada em ações coletivas e produzida pelas ações dos atores sociais, no caso, os docentes. Negando que esta seja "uma questão de urgência, prioritária, que deve ser, portanto, objeto de políticas incisivas por parte do poder público e de ações diretivas capitaneadas por organizações civis e sindicatos" (GATTI et al, 2011, p. 20).

Foucault (1995) postula que os discursos não confrontam nem associam realidade e língua, léxico e experiência; nem devem ser vistos como conjunto de signos que aí estão para remeter a este ou àquele conteúdo, a esta ou àquela representação.

Os discursos são sempre práticas que efetivamente formam os objetos que falam, e não se reduzem a um conjunto de falas, de imagens ou de textos que relacionamos para analisar. Na verdade, tudo é prática em Foucault. Isto significa dizer que na análise foucaultiana não há nada por desvelar-se, tudo está imerso em relações de poder e saber que se implicam mutuamente. "Enunciados e visibilidades, textos e instituições, falar e ver constitui práticas sociais por definição permanentemente presas, amarradas às relações de poder, que as supõem e as atualizam" (FISCHER, 2002, p. 7).

Citelli (2012), tomando dados de pesquisas educacionais, como as desenvolvidas por Bernadete Gatti, aponta uma tendência de mudança no perfil dos estudantes das licenciaturas, com mais alunos oriundos de famílias das classes populares, com formação em escolas públicas, até a graduação, e instituições privadas neste nível. Um aspecto constatado sobre a percepção dos estudantes - e provavelmente da sociedade como um todo - é que a docência possui uma remuneração baixa, com condições de trabalho ruins e com reconhecimento social menor do que sua importância.

Apesar de reconhecer a importância do professor, os jovens pesquisados afirmam que a profissão é desvalorizada socialmente, mal remunerada e com rotina desgastante. (BERTOLOTI, 2010).

Um terço dos alunos entrevistados até pensou em ser professor, mas desistiu pelos seguintes motivos: 1) falta de valorização social; 2) salários baixos e 3) rotina desgastante. (DIMENSTEIN, 2010).

Nos enunciados examinados, atratividade da docência e imagem do professor são conceitos que se interseccionam e se constroem associados a termos como trabalhar muito, mal remunerado, nenhum reconhecimento, desvalorizada, rotina desgastante, em uma construção discursiva que coloca em evidencia práticas de significação e sistemas simbólicos por meio dos quais produz significados sobre o que é ser professor.

Sendo assim, o discurso ultrapassa a simples referência a coisas, existe para além da mera utilização de letras, palavras e frases, não pode ser entendido como um fenômeno de mera expressão de algo: apresenta regularidades intrínsecas a si mesmo, através das quais é possível definir uma rede conceitual que lhe é própria. É a esse mais que o autor se refere, sugerindo que seja descrito e apanhado a partir do próprio discurso, até porque as regras de formação dos conceitos, para Foucault (1995), não residem na mentalidade nem na consciência dos indivíduos; pelo contrário, elas estão no próprio discurso e se impõem a todos aqueles que falam ou tentam falar dentro de um determinado campo discursivo.

\section{Algumas considerações}

A discussão em tela investiu na análise da produção de discursos sobre a atratividade da carreira docente na mídia, em textos jornalísticos que abordam diversos assuntos relacionados à educação e à educação escolar, com vistas a compreender as práticas de produção de subjetividade docente enunciadas em textos de reportagem sobre a atratividade da carreira de professor/professora 
da educação básica divulgados pela mídia impressa especializada. E buscou focalizar as intersecções entre "imagem do professor na mídia" e "atratividade da docência" nesta produção discursiva.

Nessa direção, da forma como se apresenta, é inegável a percepção de que no conjunto das práticas discursivas e de subjetivação, a mídia em seu dispositivo pedagógico, como propõe Fischer (1976), se configura em um artefato cultural que ocupa um lugar singular no tecido social, articulando múltiplos discursos e acionando uma política de identidade.

$\mathrm{O}$ exame dos enunciados da mídia coloca em evidência a existência de uma intencionalidade estrutural e discursiva na mídia impressa nos textos de divulgação. Na medida em que a aproximação entre o que Cataldi (2007) denomina de dois universos discursivos completamente distintos - o conhecimento técnico, por um lado, e o conhecimento social e cotidiano, por outro -, ratifica a emergência de uma construção discursiva que ao mesmo tempo em que informa o discurso técnico científico, seleciona e transmite aqueles conhecimentos que estabeleçam alguma relação com o mundo da experiência social cotidiana.
A análise dos discursos sobre a atratividade da carreira docente na mídia, em textos jornalísticos, nos permite afirmar que as formações discursivas produzidas pelos meios de comunicação que evidenciam determinadas imagens do professor operam a partir de matrizes argumentativas que selecionam, evidenciam e orientam processos de representação. E que os modos de anunciação de identidades sociais e de uma profissão estão implicados com a produção de uma percepção sobre esta. Ou seja, um conjunto das práticas discursivas sobre a docência no discurso midiático que intersecciona os conceitos de "imagem do professor na mídia" e "atratividade da docência", em que o segundo está relacionado à importância dos professores na qualidade da educação por meio dos procedimentos de exclusão, em um jogo de interdições dos enunciados pela qualidade da educação básica "formando uma grade complexa que não cessa de se modificar" (FOUCAULT, 2006, p. 9). E estão implicadas com a construção de uma imagem da docência e de valorização do professor e do ensino público como práticas de significação.

\section{REFERÊNCIAS}

BERTOLOTI, Marcelo. Prestígio zero. Revista Veja on-line, São Paulo, 07 fev. 2010. Seção Educação. Disponível em: <http://fvc.org.br/pdf/atratividades-da-carreira/07_02-atratividade-revista-veja-c_a.pdf > Acesso em: 20 jul. 2013.

BRAYNER, Flávio Henrique. Dívida pública, educação popular e republicanismo. Revista Educação e Estudos Pedagógicos, Brasília, DF, v. 89, n. 222, p. 221-232, 2008.

CATALDI, Cristiane. A divulgação da ciência na mídia impressa: um enfoque discursivo. In: CATALDI, Cristiane; GOMES, Maria Carmen Aires; MELO, Mônica Santos de Souza. Gênero discursivo, mídia e identidade. Viçosa: Editora UFV, 2007. p. 155-164.

CITELLI, Adilson. Educomunicação: imagens do professor na mídia. São Paulo: Paulinas, 2012.

COSTA, Marisa Vorraber. Estudos culturais, educação e pedagogia. Revista Brasileira de Educação, Rio de Janeiro, n. 3, p. 36-61, 2003.

A educação na cultura da mídia e do consumo. Rio de Janeiro: Lamparina, 2009.

DIMENSTEIN, Gilberto. O que você vai ser quando não crescer? Folha de São Paulo, São Paulo, 31 jan. 2010. Disponível em: <http://www1.folha.uol.com.br/fsp/cotidian/ff3101201019.htm>. Acesso em: 20 jul. 2013.

FISCHER, Rosa Maria Bueno. O estatuto pedagógico da mídia: questões de análise. Educação \& Realidade, Porto Alegre, v. 1, n. 1, 1976.

. Uma análise foucaultiana da TV: das estratégias de subjetivação da cultura. Currículo sem Fronteiras, Porto Alegre, v. 2, n. 1, 2002.

FOUCAULT, Michel. A arqueologia do saber. Rio de Janeiro: Forense Universitária, 1995. 
A ordem do discurso. São Paulo: Loyola, 2006.

GATTI, Bernadete. A.; BARRETTO, Elba Siqueira de Sá (Org.). Professores do Brasil: impasses e desafios. Brasília, DF: UNESCO, 2009.

GATTI, B. A. Et al. A atratividade da carreira docente no Brasil. In: FUNDAÇÃO VITOR CIVITA. Estudos \& pesquisas educacionais, São Paulo, n. 1, p. 139-210, maio 2010.

GATTI, Bernadete. A.; BARRETTO, Elba Siqueira de Sá; ANDRÉ, Marli Eliza Dalmazo de Afonso. Políticas docentes no Brasil: um estado da arte. Brasília, DF: UNESCO, 2011.

GIROUX, Henry A. Praticando estudos culturais nas faculdades de educação. In: SILVA, Tomaz Tadeu da (Org.). Alienígenas na sala de aula: uma introdução aos estudos culturais. Petrópolis, RJ: Vozes, 1995. p. 85-103.

HALL, Stuart. A identidade cultural na pós-modernidade. Trad. Tadeu Tomaz Silva e Guacira Lopes Louro. 4. ed. Rio de Janeiro: DP\&A, 2000.

LOURO, Guacira Lopes. Gênero, sexualidade e educação. Petrópolis, RJ: Vozes, 1997.

MADEIRA, Ana Isabel. O professor operário e apóstolo: Contributos para a história da profissão docente em contexto colonial durante a I República (1910-1926). Sísifo - Revista de Ciências da Educação, Lisboa, n. 11, p. 65-74, 2010.

NETO, José Batista. Valorização do magistério: formação, recrutamento e profissionalização. In: NETO, José Batista; SANTIAGO, Eliete (Org.). Formação de professores e prática pedagógica. Recife: Fundaj, 2006. p. 89-97.

NÓVOA, Antonio. Professores: imagem do futuro presente. Lisboa: EDUCA, 2009.

PAIVA, Paulo Henrique Apipe Avelar de; SOUTO, Romélia Mara Alves. A pouca atratividade da carreira docente: um estudo sobre o exercício da profissão entre egressos de uma Licenciatura em Matemática. Pro-Posições, Campinas, v. 24, n. 1, p. 201-224, 2013.

SHEIBE, Leda. Valorização e formação dos professores para a educação básica: questões desafiadoras para um novo plano nacional de educação. Educação e Sociedade, Campinas, v. 31, n. 112, p. 981-1000, 2010.

SILVA, Tomaz Tadeu da (Org.). Alienígenas na sala de aula: uma introdução aos estudos culturais em educação. Petrópolis, RJ: Vozes, 1995.

Identidade e diferença. Petrópolis, RJ: Vozes, 2009.

VALENZA, Cecília. Professor vai virar artigo de luxo. Gazeta do Povo, Curitiba, 22 fev. 2010. Vida e Cidadania, p. 4. Disponível em: <http://fvc.org.br/pdf/atratividades-da-carreira/22_02-atratividade-da-carreira-gazeta-do-povo. pdf $>$. Acesso em: 20 jul. 2013.

VERZOLA, Ana Luiza. Interesse pela carreira de professor diminui. O Diário.com, 21 abr. 2013. Disponível em: $<$ http://maringa.odiario.com/empregos/noticia/739212/interesse-pela-carreira-de-professor-diminui/>. Acesso em: 20 jul. 2013.

Recebido em: 07.05.2014

Aprovado em: 03.10.2014 